\title{
Effect of Duration of Diabetes Mellitus Type-2 on Electrophysiological Indices of Sensorimotor Nerves in Subjects with Diabetic Polyneuropathy: A Cross-Sectional Study
}

\author{
Ahsan Numan ${ }^{1,4}$, Abdul Basit Qureshi' ${ }^{2}$, Fehmeda Farrukh Khan ${ }^{3}$, Faisal Masud ${ }^{3}$, \\ Ijaz Ahmad ${ }^{4}$, Kamran Ashraf, , Nisar Ahmad ${ }^{5}$, Muhammad Shahbaz Yousaf ${ }^{4}$, \\ Imtiaz Rabbani ${ }^{4}$, Hafsa Zaneb ${ }^{6}$ and Habib Rehman ${ }^{4 *}$ \\ ${ }^{1}$ Department of Neurology, Services Institute of Medical Sciences, Lahore \\ ${ }^{2}$ Department of Surgery, Services Institute of Medical Sciences, Lahore \\ ${ }^{3}$ Department of Endocrinology, Services Institute of Medical Sciences, Lahore \\ ${ }^{4}$ Department of Physiology, University of Veterinary and Animal Sciences, Lahore \\ ${ }^{5}$ Department of Parasitology, University of Veterinary and Animal Sciences, Lahore \\ ${ }^{6}$ Department of Anatomy, University of Veterinary and Animal Sciences, Lahore
}

\begin{abstract}
A B S T R A C T
The study investigated the effect of duration of diabetes mellitus type- 2 on the electrophysiological characteristics of sensorimotor nerves in patients with clinical diabetic polyneuropathy (DSP). Clinical diagnosis of DSP was assessed with the Michigan Neuropathy Screening Instrument. The diagnosed patients with DMT2 were randomly distributed into 2 groups. Group-I $(n=79)$ included the patients with DSP having $<10$ years of duration of DMT2, called short duration, while DSP patients of Group-II ( $\mathrm{n}=$ 49) had duration of DMT2 for $\geq 10$ years, thereafter called long duration. The patients in both groups were compared with their corresponding duration of DMT2-matched individuals without clinical DSP. Latency, conduction velocity and amplitude of four sensory nerves (median, ulnar, peroneal and sural) and four motor nerves (median, ulnar, peroneal and tibial) were measured. Results demonstrated significant differences in all electrophysiological attributes of motor nerves except tibial nerve of the DSP patients compared to DMT2 patients in the short duration group. Similar results were noticed for sensory nerves except ulnar nerve in DSP patients. For long duration group, DSP nearly affected all 3 electrophysiological characteristics in both sensory and motor nerves. When short and long duration groups were compared with each other for electrophysiological indices for their respective nerves, functional impairment of sensorimotor nerves was more obvious in DSP patients for longer duration compared to the DSP patients for shorter duration. To conclude, long standing DMT2 deteriorates the nerve conduction attributes in the sensorimotor nerves of patients showing clinical DSP.
\end{abstract}

\begin{tabular}{l} 
Article Information \\
Received 15 June 2015 \\
Revised 11 May 2019 \\
Accepted 22 July 2020 \\
Available online 14 May 2021 \\
Authors' Contribution \\
\hline AN, ABQ, KA, IA and HR designed \\
the experiment. NA, FFK, FM, \\
MSY, IR and HZ performed the \\
experimental work and collated the \\
data. AN, FFK, and MSY wrote the \\
manuscript. HR, HZ supervised the \\
final write-up of the manuscript. AN, \\
HR, IR and FM analyzed the data. \\
Key words \\
\hline Diabetes mellitus type-2, Diabetic \\
sensorimotor polyneuropathy
\end{tabular}

\section{INTRODUCTION}

$\mathrm{D}$ iabetes mellitus (DM), a metabolic disorder, is associated with defects in insulin secretion and/or actions resulting in hyperglycemia. Generally, DM has been categorized in two forms. Type-1 DM, which is a ketosisprone form of diabetes resulting due to autoimmune or idiopathic destruction of pancreatic beta-cells. On the other hand, type-2 DM is primarily due to insulin resistance or a concomitant defect in secretory functions of beta-cell. In Pakistan, 5.0 million people are affected with DM that may

\footnotetext{
Corresponding author: habibrehman@uvas.edu.pk 0030-9923/2021/0004-1321 \$9.00/0

Copyright 2021 Zoological Society of Pakistan
}

go up to $13.9 \%$ in 2030 (Wild et al., 2004). Chronic hyperglycemia results in the development of a complex form of neuropathy. The neuropathic syndromes linked with DM are mainly divided into two major categories: the symmetrical neuropathies and the asymmetrical neuropathies. Diabetic sensorimotor polyneuropathy (DSP) is the most common form of diabetic complication, affecting about $50 \%$ of diabetic individuals (Dyck et al., 2010). The typical DSP is a chronic, symmetrical, length-dependent involving motor, sensory, and autonomic nerves (Boulton et al., 2005). The underlying pathophysiology of DSP is still to be elucidated. However, hyperglycemia has been found to be implicated in the development and progression of DSP (Shaw and Zimmet, 1999). Long standing hyperglycemia 
is a key initiator for degenerative neuronal changes that include demyelination, axonal atrophy, nerve fiber loss, and abnormal nerve fibers repair. These abnormalities reduced the nerve conduction velocity and amplitude. Diabetes duration raises the risk of neuropathy, but link between prevalence and duration may depend in part on the age of patient, which itself is a risk factor (Shaw and Zimmet, 1999).

A body of evidences demonstrated that duration of DM invariably influences both motor and sensory nerve function in subjects with clinical neuropathy (Lee et al., 2010; Sultana et al., 2009, 2010). It has been observed lower motor nerve conduction velocities in ulnar, tibial and peroneal nerves, but not in median nerve in DSP patients with longer duration of DMT2 than the DSP patients with shorter duration of DMT2 (Hussain et al., 2014). On the contrary, others found that duration of DM did not affect the latency, conduction velocity or amplitude of motor ulnar nerve in the DSP patients (Sultana et al., 2009). The conduction velocity of sural nerve, not median sensory or ulnar sensory nerves, was marginally reduced in DSP individuals with longer duration of DMT2 than in the DSP individuals with short duration of DMT2 (Sultana et al., 2010; Hussain et al., 2014). Shekharappa et al. (2011) concluded that there was decrease in nerve conduction velocity and amplitude in diabetic patients having poor glycemic control.

The influence of duration of DM on nerve conduction measures is not clearly understood. It seems that how the duration of DM influences the nerve conduction measures is still not fully known. Moreover, to the best of our knowledge, there is no single report describing the complete profile of electrophysiological abnormalities in sensorimotor nerves. Therefore, we sought to investigate whether duration of DMT2 has any impact on the nerve conduction abnormalities four motor nerves (ulnar, median, tibial and peroneal) and four sensory nerves (ulnar, median, sural and peroneal).

\section{MATERIALS AND METHODS}

This cross-sectional study was conducted at the Diabetes Management Center (DMC), Service Institute of Medical Sciences, Lahore, Pakistan. All individuals were recruited for the study that visited the DMC for medical advice during August, 2013 to December, 2013. The patients included in the study were known diabetic and written consent was obtained. The study was approved by the Ethical Committee, Service Institute of Medical Sciences, Lahore.

Anthropometric measurements
Diabetes was diagnosed according to revised "American Diabetes Association Criteria", based on blood glucose levels of $126 \mathrm{mg} / \mathrm{dl}(>6.1 \mathrm{mmol} / \mathrm{l})$ and $200 \mathrm{mg} / \mathrm{dl}(>11.1 \mathrm{mmol} / \mathrm{l})$ on fasting and two hours postprandial. The inclusion criteria for recruiting the subjects were DM patients aged $>18$ years. The subjects with no previous history of any systemic illness related to peripheral neuropathy (alcoholic neuropathy, renal failure, malnutrition), any neuromuscular disorder (chronic polyneuropathy, Guillain Barree Syndrome, myopathy, familial polyneuropathy), trauma of the nerve to be examined, neuropathies linked with external toxins, drugs or metals were not included in the study.

After obtaining their written consent, a questionnaire that included general information, health status or any other disease, duration of diabetes, type of medication, and history of foot ulcer, angina, hypertension, stroke or smoking were completed either by the patient or attendant. Physical examination was also carried our as per routine that included measurement of height, weight, waist and hip circumferences.

\section{Laboratory measurements}

For determining various biochemical determinants, venous blood was drained from every individual with DM. Plasma glucose level was measured by glucose oxidase method. Concentration of glycated hemoglobin $\left(\mathrm{HbA}_{1 \mathrm{c}}\right)$ was determined using a high-pressure liquid chromatograph (HLC-723G7, Tosoh Corporation, Japan). Serum urea, creatinine, and total lipids profile (cholesterol, triglycerides, HDL and LDL) were also determined using commercial kits with a spectrophotometer.

Diagnosis of diabetic sensorimotor polyneuropathy (DSP) Diagnosis of the DSP was assessed using the "Michigan Neuropathy Screening Instrument" (MNSI) as described earlier (Herman et al., 2012). The MNSI includes two separate assessments: A 15-item selfadministered questionnaire (called history) and a lower extremity examination (physical assessment). The MNSI-questionnaire (part A) includes 15 "yes" or "no" questions on foot sensation. Part B of MNSI consists of a standardized physical examination including: 1) inspection of the feet for deformities, 2) ulceration; 3) grading of ankle reflexes; 4) a semi-quantitative assessment of sensation of vibration at the dorsum of the great toes; 5) perception of monofilaments.

\section{Electro-physiological measurements}

The latencies, amplitudes and conduction velocities of four motor nerves (ulnar, median, tibial and peroneal) and four sensory nerves (ulnar, median, sural and peroneal) 
were measured in the right sides of upper and lower limbs using an electro-myograph (Nihon Kohden Toshiba, Japan). Both motor conduction velocity (MCV) and sensory conduction velocity (SCV) were measured using electro-conductive gel coated electrodes on skin surface at $32-33^{\circ} \mathrm{C}$. For motor nerves, electrical stimulation of a peripheral nerve was carried out, while, recording was made from a muscle supplied by the nerve. The time (msec) taken by electrical impulses to move from the site of stimulation to the site of recording was measured and designated as latency. The ratio of distance between different stimulating electrodes $(\mathrm{mm})$ to difference in latencies was regarded as nerve conduction velocity $(\mathrm{m} / \mathrm{s})$. Stimulation of both sensorimotor nerves was loaded at 15 $\mathrm{mA}$ for $0.2 \mathrm{msec}$ for conduction velocity and the stimulation intensity was raised up to $25 \mathrm{~mA}$. The amplitudes were measured from initial positive peak to the negative peak or from the baseline to the negative peak if there was no initial positive peak. The diagnosed patients of DSP were divided in two groups depending upon DMT2 duration. Group-I ( $n=69$ ) with less than 10 years and Group-II ( $n=49$ ) with $\geq 10$ years. The baseline characteristics were also compared with the patients similar in age, sex and duration of DMT2 showing no clinical signs or symptoms of DSP.

\section{Statistical analyses}

All statistical tests were performed using SPSS for Window (SPSS Inc, New York). Data are expressed as Mean \pm SD. The Kolmogorov-Smirnov test was employed to test the normal distribution of the data before statistical analysis was performed. For gender, the $x^{2}$-test was used to compare association between two groups. For remaining variables, Student's $t$ test was used for continuous variables except when a normal distribution was not achieved, in that case the Mann-Whitney U test was employed. Statistical differences were predetermined at $\mathrm{p}<0.05$, whereas $\mathrm{p}<0.1$ was designated as trend.

\section{RESULTS}

\section{Anthropometric and blood biochemical characteristics}

In the present study, 128 patients with known DSP were screened. Out of 128 individual, 79 had history of DMT2 for $<10$ years (Group-I, thereafter called short duration), 49 having DSP had known history of DMT2 for $\geq 10$ years (Group-II, long duration). For comparison, 69 and 40 individuals of shorter and longer duration with known DMT2, with no signs/symptoms of DSP were also included, respectively. Anthropometric and serum biochemical characteristics of patients with or without clinical symptoms of DSP are shown in Table I. There was no difference in age, DMT2 duration, weight, height, BMI, waist and hip circumferences in individuals with or without clinical neuropathy in both groups. The HBA and serum cholesterol were higher in subjects with clinical DSP compared with the subjects without clinical DSP in both groups (Table I). Serum triglycerides tended to be higher in Groups-I $(\mathrm{p}=0.095)$ and II $(\mathrm{P}=0.072)$ when compared with respective age-matched diabetic patients without clinical DSP (Table I). Serum concentrations of LDL, HDL, urea and creatinine remained unaffected ( $p$ $>0.05)$ in patients with or without clinical DSP in both groups except higher $(\mathrm{P}<0.01)$ concentration of serum LDL in group II patients with clinical DSP when compared with diabetic individuals without clinical DSP (Table I). As far as patients with DSP are concerned, the mean age $(\mathrm{P}<0.001)$, duration of DMT2 $(\mathrm{P}<0.001)$, concentrations of $\mathrm{HbA}_{1} \mathrm{c}(\mathrm{p}<0.01)$, serum cholesterol $(\mathrm{p}<0.001)$ and LDL $(p<0.001)$ were more in Group-I compared with the Group-II DM (Table I). On the other hand, weight, hip circumference and BMI were lower $(\mathrm{P}<0.05)$ in patients of DSP in Group-I compared with DSP patients in Group-II (Table I).

\section{Nerve conduction studies (NCS)}

In both age groups, MCVs and amplitudes were reduced $(p<0.001)$ in the subjects with DSP compared with the respective diabetic control group for motor components of median, tibial and peroneal nerves (Table II). The latencies were also delayed $(\mathrm{p}<0.001)$ in the patients with clinical DSP group than in the diabetic control groups (Table II). However, all three electrophysiological attributes remained unaffected for the motor ulnar nerve independent of duration of DMT2 (Table II). When comparison of DSP patients were made between two groups, it was found that duration of DMT2 affected more severely in Group-II as amplitudes, latencies and MVCs were dearranged for motor median, motor tibial and motor peroneal nerves (Table II). However, only amplitude was lower $(\mathrm{P}<0.05)$ in DSP patients in Group-II (6.04 \pm 1.01$)$ compared with DSP patients in Group-I (6.57 \pm 1.63$)$ without any effect on latency and MCV.

For sensory nerves, similar outcomes were also observed for amplitudes, SCVs and latencies of sensory median, sural and sensory peroneal nerves (Table III). As observed for motor nerves, amplitudes and SCVs of all four sensory nerves were decreased in DSP patients of Group-II compares with the DSP patients of Group-I with concomitant prolonged latency in the former group compared with the latter (Table III). 
Table I. Comparison of anthropometric and serum biochemical characteristics of diabetes mellitus type-2 (DMT2) patients with or without clinical sensorimotor polyneuropathy (DSP) based on duration of DMT2.

\begin{tabular}{|c|c|c|c|c|c|}
\hline \multirow[t]{2}{*}{ Parameter } & \multicolumn{2}{|c|}{${ }^{*}$ Group-I } & \multicolumn{2}{|c|}{${ }^{\ddagger}$ Group-II } & \multirow{2}{*}{$\begin{array}{l}\text { p-values for } \\
\text { DSP group-I } \\
\text { vs. group-II }\end{array}$} \\
\hline & $\begin{array}{l}\text { With clinical } \\
\text { DSP }(n=79)\end{array}$ & $\begin{array}{l}\text { Without clinical } \\
\text { DSP }(n=69)\end{array}$ & $\begin{array}{l}\text { With clinical } \\
\text { DSP }(n=49)\end{array}$ & $\begin{array}{l}\text { Without clinical } \\
\text { DSP }(n=40)\end{array}$ & \\
\hline Gender (male/female, $n$ ) & $26 / 53$ & $23 / 46$ & $16 / 33$ & $17 / 23$ & 0.975 \\
\hline Age (years) & $50.35 \pm 8.41$ & $51.88 \pm 9.33$ & $56.53 \pm 8.69$ & $54.25 \pm 8.00$ & 0.000 \\
\hline Duration of DM (years) & $3.40 \pm 2.34$ & $3.80 \pm 2.28$ & 14. $30 \pm 0.50$ & $12.72 \pm 0.51$ & 0.000 \\
\hline Weight $(\mathrm{kg})$ & $76.77 \pm 14.07$ & $73.88 \pm 14.45$ & $71.48 \pm 14.99$ & $70.62 \pm 18.16$ & 0.046 \\
\hline Height $(\mathrm{cm})$ & $156.82 \pm 9.49$ & $156.90 \pm 9.22$ & $157.16 \pm 9.37$ & $157.90 \pm 10.39$ & 0.843 \\
\hline Waist Circumference $(\mathrm{cm})$ & $105.29 \pm 10.64$ & $105.33 \pm 11.20$ & $102.96 \pm 11.64$ & $100.02 \pm 14.14$ & 0.243 \\
\hline Hip Circumference (cm) & $106.78 \pm 10.76$ & $104.67 \pm 10.01$ & $102.90 \pm 10.73$ & $100.98 \pm 13.61$ & 0.049 \\
\hline $\operatorname{BMI}\left(\mathrm{kg} / \mathrm{m}^{2}\right)$ & $31.51 \pm 4.88$ & $30.22 \pm 5.66$ & $29.25 \pm 6.18$ & $28.19 \pm 5.74$ & 0.024 \\
\hline $\mathrm{HbA}_{1 \mathrm{c}}(\%)$ & $7.94 \pm 1.49 * *$ & $6.98 \pm 1.25$ & $8.91 \pm 1.67 * *$ & $7.14 \pm 1.32$ & 0.001 \\
\hline Cholesterol (mmol/L) & $5.97 \pm 1.08^{*}$ & $5.55 \pm 1.14$ & $6.70 \pm 0.82 * *$ & $5.91 \pm 1.12$ & 0.000 \\
\hline Triglycerides (mmol/L) & $3.31 \pm 0.57$ & $3.47 \pm 0.57$ & $3.47 \pm 0.57$ & $3.25 \pm 0.55$ & 0.121 \\
\hline $\mathrm{HDL}(\mathrm{mmol} / \mathrm{L})$ & $4.01 \pm 0.52$ & $3.98 \pm 0.46$ & $3.95 \pm 0.45$ & 4. $01 \pm 0.52$ & 0.503 \\
\hline $\mathrm{LDL}(\mathrm{mmol} / \mathrm{L})$ & $1.09 \pm 0.11$ & $1.07 \pm 0.10$ & $1.40 \pm 0.32 * *$ & $1.05 \pm 0.68$ & 0.000 \\
\hline Urea $(\mathrm{mmol} / \mathrm{L})$ & $6.80 \pm 1.28$ & $6.49 \pm 1.70$ & $6.59 \pm 1.35$ & $6.29 \pm 1.11$ & 0.386 \\
\hline
\end{tabular}

Values are represented as Mean $\pm \mathrm{SD}$; DMT, diabetes mellitus type; BMI, body mass index; $\mathrm{HbA}_{1 \mathrm{c}}$, glycosylated haemoglobin; LDL, low density lipoproteins; HDL, high density lipoproteins. ${ }^{*}$ Groups-I and II include patients with duration of $<10$ years and $\geq 10$ years DMT2 with or without clinical DSP; $* * *$ Means significant difference from diabetic control group at $\mathrm{p}<0.05$ and $\mathrm{p}<0.01$, respectively.

Table II. Comparison of electrophysiological indices of motor nerves in diabetic mellitus type-2 (DMT2) with clinical diabetic sensorimotor polyneuropathy (DSP) compared with diabetic type-2 mellitus patients without DSP.

\begin{tabular}{|c|c|c|c|c|c|c|c|}
\hline \multirow[t]{2}{*}{ Indices } & \multicolumn{2}{|c|}{ *Group-I } & \multirow[t]{2}{*}{ p-value } & \multicolumn{2}{|c|}{ *Group-II } & \multirow[t]{2}{*}{ p-value } & \multirow{2}{*}{$\begin{array}{l}\text { p-values for } \\
\text { DSP Group I } \\
\text { vs. Group-II }\end{array}$} \\
\hline & $\begin{array}{l}\text { With clinical } \\
\text { DSP }(n=79)\end{array}$ & $\begin{array}{l}\text { Without clinical } \\
\text { DSP }(n=69)\end{array}$ & & $\begin{array}{l}\text { With clinical } \\
\text { DSP }(n=49)\end{array}$ & $\begin{array}{l}\text { Without clinical } \\
\text { DSP }(n=40)\end{array}$ & & \\
\hline \multicolumn{8}{|l|}{ Median nerve } \\
\hline Latency (msec) & $4.76 \pm 0.43$ & $3.99 \pm 0.47$ & $<0.001$ & $5.46 \pm 0.93$ & $4.06 \pm 0.26$ & $<0.001$ & $<0.001$ \\
\hline Amplitude (mv) & $3.84 \pm 0.87$ & $6.86 \pm 0.75$ & $<0.001$ & $3.40 \pm 0.83$ & $6.60 \pm 0.73$ & $<0.001$ & 0.005 \\
\hline Velocity(m/s) & $45.94 \pm 2.24$ & $51.39 \pm 3.57$ & $<0.001$ & $42.42 \pm 3.80$ & $51.15 \pm 2.72$ & $<0.001$ & $<0.001$ \\
\hline \multicolumn{8}{|l|}{ Ulnar nerve } \\
\hline Latency (msec) & $3.18 \pm 0.66$ & $3.04 \pm 0.40$ & 0.842 & $3.23 \pm 0.75$ & $3.20 \pm 0.45$ & 0.842 & 0.703 \\
\hline Amplitude (mv) & $6.57 \pm 1.63$ & $6.87 \pm 0.99$ & 0.244 & $6.04 \pm 1.01$ & $6.28 \pm 0.89$ & 0.244 & 0.046 \\
\hline $\operatorname{Velocity}(\mathrm{m} / \mathrm{s})$ & $49.28 \pm 5.85$ & $50.37 \pm 3.35$ & 0.170 & $48.32 \pm 5.10$ & $49.62 \pm 3.37$ & 0.170 & 0.350 \\
\hline \multicolumn{8}{|l|}{ Tibial nerve } \\
\hline Latency (msec) & $5.98 \pm 0.57$ & $5.36 \pm 0.32$ & $<0.001$ & $6.41 \pm 0.65$ & $5.55 \pm 0.28$ & $<0.001$ & $<0.001$ \\
\hline Amplitude (mv) & $3.23 \pm 0.65$ & $4.78 \pm 0.95$ & $<0.001$ & $2.13 \pm 0.58$ & $4.71 \pm 1.08$ & $<0.001$ & $<0.001$ \\
\hline $\operatorname{Velocity}(\mathrm{m} / \mathrm{s})$ & $36.52 \pm 5.52$ & $43.98 \pm 5.74$ & $<0.001$ & $34.08 \pm 5.27$ & $44.22 \pm 4.02$ & $<0.001$ & 0.015 \\
\hline \multicolumn{8}{|l|}{ Peroneal nerve } \\
\hline Latency (msec) & $7.02 \pm 1.03$ & $6.00 \pm 0.65$ & $<0.001$ & $8.06 \pm 0.79$ & $5.89 \pm 0.34$ & $<0.001$ & $<0.001$ \\
\hline Amplitude (mv) & $1.35 \pm 0.36$ & $2.45 \pm 0.47$ & $<0.001$ & $1.12 \pm 0.39$ & $2.18 \pm 0.38$ & $<0.001$ & 0.001 \\
\hline $\operatorname{Velocity}(\mathrm{m} / \mathrm{s})$ & $39.93 \pm 3.89$ & $46.92 \pm 3.18$ & $<0.001$ & $33.10 \pm 9.62$ & $45.40 \pm 3.35$ & $<0.001$ & $<0.001$ \\
\hline
\end{tabular}

Values are represented as Mean \pm SD; *Groups-I and II include patients with duration of $<10$ years and $\geq 10$ years DMT2 with or without clinical DSP. 
Table III. Comparison of electrophysiological indices of sensory nerves in diabetic mellitus type-2 (DMT2) with clinical diabetic sensorimotor polyneuropathy (DSP) compared with diabetic type-2 mellitus patients without DSP.

\begin{tabular}{|c|c|c|c|c|c|c|c|}
\hline \multirow[t]{2}{*}{ Indices } & \multicolumn{2}{|c|}{${ }^{*}$ Group-I } & \multirow[t]{2}{*}{ p-value } & \multicolumn{2}{|c|}{ *Group-II } & \multirow[t]{2}{*}{ p-value } & \multirow{2}{*}{$\begin{array}{l}\text { p-values for DSP } \\
\text { Group I vs. II }\end{array}$} \\
\hline & DSP & DMT2 & & DSP & DMT2 & & \\
\hline \multicolumn{8}{|l|}{ Median nerve } \\
\hline Latency (msec) & $3.70 \pm 0.72$ & $3.44 \pm 0.51$ & 0.014 & $4.09 \pm 0.67$ & $3.67 \pm 0.56$ & 0.002 & 0.003 \\
\hline Amplitude (mv) & $17.01 \pm 3.32$ & $19.76 \pm 2.60$ & $<0.001$ & $12.95 \pm 2.82$ & $20.07 \pm 1.88$ & $<0.001$ & $<0.001$ \\
\hline $\operatorname{Velocity}(\mathrm{m} / \mathrm{s})$ & $45.94 \pm 5.32$ & $51.97 \pm 4.20$ & $<0.001$ & $42.46 \pm 7.74$ & $50.45 \pm 4.78$ & $<0.001$ & 0.007 \\
\hline \multicolumn{8}{|l|}{ Ulnar nerve } \\
\hline Latency (msec) & $3.48 \pm 0.52$ & $3.23 \pm 0.57$ & 0.006 & $3.74 \pm 0.43$ & $2.86 \pm 0.30$ & $<0.001$ & 0.004 \\
\hline Amplitude (mv) & $16.65 \pm 3.29$ & $17.17 \pm 2.26$ & 0.273 & $14.93 \pm 3.00$ & $17.50 \pm 1.72$ & $<0.001$ & 0.003 \\
\hline Velocity(m/s) & $50.08 \pm 4.76$ & $51.21 \pm 2.95$ & 0.092 & $48.30 \pm 6.09$ & $51.45 \pm 2.67$ & 0.003 & 0.068 \\
\hline \multicolumn{8}{|l|}{ Sural nerve } \\
\hline Latency (msec) & $4.90 \pm 0.34$ & $4.05 \pm 0.32$ & $<0.001$ & $5.43 \pm 0.30$ & $4.12 \pm 0.22$ & $<0.001$ & $<0.001$ \\
\hline Amplitude (mv) & $4.91 \pm 0.80$ & $6.41 \pm 0.37$ & $<0.001$ & $3.72 \pm 0.65$ & $6.09 \pm 0.54$ & $<0.001$ & $<0.001$ \\
\hline Velocity(m/s) & $37.10 \pm 2.64$ & $41.57 \pm 3.87$ & $<0.001$ & $32.61 \pm 6.50$ & $39.55 \pm 2.07$ & $<0.001$ & $<0.001$ \\
\hline \multicolumn{8}{|l|}{ Peroneal nerve } \\
\hline Latency (msec) & $4.69 \pm 0.35$ & $3.92 \pm 0.29$ & $<0.001$ & $5.21 \pm 0.47$ & $4.03 \pm 0.22$ & $<0.001$ & $<0.001$ \\
\hline Amplitude (mv) & $5.02 \pm 0.48$ & $6.40 \pm 0.50$ & $<0.001$ & $3.93 \pm 0.76$ & $5.92 \pm 0.65$ & $<0.001$ & $<0.001$ \\
\hline Velocity $(\mathrm{m} / \mathrm{s})$ & $35.17 \pm 4.26$ & $40.97 \pm 3.78$ & $<0.001$ & $32.61 \pm 5.80$ & $39.27 \pm 1.75$ & $<0.001$ & 0.009 \\
\hline
\end{tabular}

Values are represented as Mean $\pm \mathrm{SD} ; *$ Group-I and Group-II include patients with duration of $<10$ and $\geq 10$ years DMT2 with or without clinical DSP.

\section{DISCUSSION}

The study revealed that abnormalities in sensorimotor nerve functions were seen in both short duration and long duration groups DMT2 with clinical DSP when compared with the corresponding DMT2 subjects without clinical DSP. However, this pattern of functional deterioration could not be observed in ulnar motor nerve independent of duration of DMT2 that is similar to previous reports (Sultana et al., 2009; Hussain et al., 2014). This shows that DMT2 affects more frequently in the lower limbs compared with the upper limbs. A body of evidences also demonstrated that motor nerve functions of lower limbs are more frequently affected than the motor nerves of upper limb (Halar et al., 1982; Sultana et al., 2009; Hussain et al., 2014). The results of the present study are similar to the previous findings demonstrating that MCV and amplitudes of median, tibial and peroneal nerves are significantly reduced in DMT2 patients with peripheral neuropathy (Sultana et al., 2009; Hussain et al., 2014). In the current study, the motor nerve functions of median, tibial and peroneal nerves were more deteriorated in DSP subjects with longer duration (Group-I) compared with the DSP patients with relative shorter duration of DMT2 (Group-II, Table II). Similar to our results, others also failed to describe the effect of duration of DMT2 on MCV of ulnar nerve in DSP individuals (Sultana et al., 2009).

Presently, all the electrophysiological attributes of sensory serves were invariably affected in the DSP patients independent of long duration DMT2. Similar findings were also reported earlier mentioning that SCV of median and sural nerves were decreased in the patients with clinical peripheral neuropathy compared with DMT2 patients without any clinical peripheral neuropathy. In the present study, we found that sensory nerve dysfunctions were more prominent in the DSP patients of GroupII compared with the neuropathic subjects of Group-I (Table III). Similar to our results, it has been found that SCV of ulnar sural nerves were reduced in neuropathetic individuals with relatively long standing DMT2 compared with the DSP individuals with short duration of DMT2 (Sultana et al., 2010; Hussain et al., 2014). It is generally accepted that DSP may start very early in diabetic patients and frequently involves sensory fibers (Halar et al., 1982; Karlssona et al., 2019). Various evidences also suggest that sensory neuropathy is more common in long standing diabetic subjects (Gregersen, 1967; Vinik et al., 1992).

It seems that duration of DMT2 influences the functional electrophysiological characteristics of sensory and motor nerves. It was found that the electrophysiological 
parameters of motor and sensory nerves are negatively correlated with diabetes duration, confirming the long standing of diabetes severely affects the functioning of nerves (Valensi et al., 1997). A negative correlation of nerve conduction velocity with duration of diabetes has also been described by several authors (Gregersen, 1967; Charles et al., 2010).

In the current study, higher levels of $\mathrm{HbA}_{1 \mathrm{c}}$ along with dyslipidemia have been found in the subjects with DSP when compared with the patients with DMT2. Both indicators are also significant when Group-I and GroupII were compared (Table I). Previous studies indicated that glycemic control influenced the nerve conduction properties as poor glycemic control retarded the nerve conduction with diminished amplitude (DCCT Research Group, 1988; Charles et al., 2010; Shekharappa et al., 2011). In a 10-year follow up study (Morimoto et al., 2012), it was found that sensory nerve conduction velocity were more reduced in DSP patients with higher $\mathrm{HbA}_{1 \mathrm{c}}$ (8.5\%) compared with low level (6.6\%). Poor glycemic control induced biochemical abnormalities in peripheral nerves that have been implicated in impaired nerve conduction (Greene et al., 1985). It seems that nerve dysfunction in the DSP patients may be attributed, at least, to bad glycemic control. It appears that optimal glycemic control may not only slow down the progression of DSP but also correct the nerve conduction abnormalities. For instance, anti-diabetes therapy improved the MCV of the median, peroneal and tibial nerves in patients whose levels of hyperglycemia were lowered without affecting sensory nerves (Graf et al., 1981).

Besides, duration of $\mathrm{DM}$ and $\mathrm{HbA}_{1 \mathrm{c}}$, we also found hypercholesterolemia and marginally higher triglyceridemia in patients of DMT2 showing clinical neuropathy independent of duration of DMT2 in both groups. Wiggin et al., 2009 found that individuals with advancing DSP exhibited higher levels of triglyceride and reduction in peroneal motor nerves conduction velocities (Wiggin et al., 2009). It has been shown that therapy with statins had an ameliorative effect on the development and advancement of DSP suggesting that correction of triglyceridemia may, at least, delay the development and progression of DSP (Davis et al., 2008). The exact mechanism that how the elevated triglycerides are implicated to induce assault to the nerve functions is not still known but may be due to dysregulated-lipid metabolism in neurons (Wiggin et al., 2009).

In summary, we found that nerve conduction attributes became deteriorated as severity of DSP increases with the DMT2 duration and these were similar for both motor and sensory nerves. Lower limbs are affected earlier than upper limbs. Though the current study is a cross-sectional and it is difficult to infer from the results, but it is presumed that functional characteristics of nerves may be influenced by many factors like duration of DM, proper glycemic control, and serum lipid profile etc. However, prospective studies are needed to confirm this assumption.

\section{Statement of conflict of interest}

The authors have declared no conflict of interest.

\section{REFERENCES}

Boulton, A.J., Vinik, A.I., Arezzo, J.C., Bril, V., Feldman, E.L., Freeman, R., Malik, R.A., Maser, R.E., Sosenko, J.M. and Ziegler, D., 2005. Diabetic neuropathies a statement by the Amercian Diabetic Association. Diab. Care, 28: 956-962. https://doi. org/10.2337/diacare.28.4.956

Charles, M., Soedamah-Muthu, S.S., Tesfaye, S., Fuller, J.H., Arezzo, J.C., Chaturvedi, N. and Witte, D.R., 2010. Low peripheral nerve conduction velocities and amplitudes are strongly related to diabetic microvascular complications in type 1 diabetes. The EURODIAB prospective complications study. Diab. Care, 33: 2648-2653. https://doi.org/10.2337/ dc10-0456

Davis, T.M.E., Yeap, B.B., Davis, W.A. and Bruce, D.G., 2008. Lipid-lowering therapy and peripheral sensory neuropathy in type 2 diabetes: The Fremantle Diabetes Study. Diabetologia, 51: 562566. https://doi.org/10.1007/s00125-007-0919-2

DCCT Research Group. 1988. Factors in development of diabetic neuropathy: baseline analysis of neuropathy in feasibility phase of Diabetes Control and Complications Trial (DCCT). Diabetes, 37: 476-481. https://doi.org/10.2337/diab.37.4.476

Dyck, P.J., Overland, C.J., Low, P.A., Litchy, W.J., Davies, J.L., Dyck, P.J., O’Brien, P.C., Albers, J.W., Andersen, H., Bolton, C.F., England, J.D., Klein, C.J., Llewelyn, J.G., Mauermann, M.L., Russell, J.W., Singer, W., Smith, A.G., Tesfaye, S. and Vella, A., 2010. Signs and symptoms versus nerve conduction studies to diagnose diabetic sensorimotor polyneuropathy. Muscle Nerve, 42: 157-164. https://doi.org/10.1002/mus.21661

Graf, R.J., Halter, J.B., Pfeifer, M.A., Halar, E., Brozovich, F. and Porte, D., 1981. Glycemic control and nerve conduction abnormalities in non-insulindependent diabetic subjects. Annl. Int. Med., 94: 307-311. https://doi.org/10.7326/0003-4819-94-3307

Greene, D.A., Lattimer, S., Ulbrecht, J. and Carroll, P., 1985. Glucose-induced alterations in nerve 
metabolism: current perspective on the pathogenesis of diabetic neuropathy and future directions for research and therapy. Diab. Care, 8: 290-299. https://doi.org/10.2337/diacare.8.3.290

Gregersen, G., 1967. Diabetic neuropathy: Influence of age, sex, metabolic control, and duration of diabetes on motor conduction velocity. Neurology, 17: 972 980. https://doi.org/10.1212/WNL.17.10.972

Halar, E.M., Graf, R.J., Halter, J.B., Brozovich, F.V. and Soine, T.L., 1982. Diabetic neuropathy: A clinical, laboratory and electrodiagnostic study. Arch. Phys. Med. Rehabil., 63: 298-303.

Herman, W.H., Pop-Busui, R., Braffett, B.H., Martin, C.L., Cleary, P.A., Albers, J.W. and Feldman, E.L., 2012. Use of the Michigan Neuropathy Screening Instrument as a measure of distal symmetrical peripheral neuropathy in type-1 diabetes: Results from the Diabetes Control and Complications Trial/Epidemiology of diabetes interventions and complications. Diab. Med., 29: 937-944. https:// doi.org/10.1111/j.1464-5491.2012.03644.x

Hussain, G., Rizvi, S.A.A., Singhal, S., Zubair and M., Ahmad, J., 2014. Cross sectional study to evaluate the effect of duration of type 2 diabetes mellitus on the nerve conduction velocity in diabetic peripheral neuropathy. Diab. Metab. Syndr., 8: 48-52. https:// doi.org/10.1016/j.dsx.2013.02.003

Karlssona, P., Hinckerc, A.M., Jensena, T.S., Freemand, R., Haroutounian, S., 2019. Structural, functional, and symptom relations in painful distal symmetric polyneuropathies: A systematic review. Pain, 160: 286-297. https://doi.org/10.1097/j. pain.0000000000001381

Lee, S.S., Han, H.S. and Kim. H., 2010. A 5-year follow-up nerve conduction study for the detection of subclinical diabetic neuropathy in children with newly diagnosed insulin-dependent diabetes mellitus. Pediatr. Diab., 11: 521-528. https://doi. org/10.1111/j.1399-5448.2009.00636.x

Morimoto, J., Suzuki, Y., Tada, A., Akui, M., Ozawa,
Y. and Maruyama, T., 2012. Time-course changes in nerve conduction velocity (NCV) in type 2 diabetes. J. Diab. Complic., 26: 237-240. https:// doi.org/10.1016/j.jdiacomp.2012.03.008

Shaw, J.E. and Zimmet, P.Z., 1999. The epidemiology of diabetic neuropathy. Diab. Rev., 7: 245-52.

Shekharappa, K.P., Srinivas, A.K., Vedavathi, K.J. and Venkatesh, G.A., 2011. A study on the utility of nerve conduction studies in type 2 diabetes mellitus. J. clin. Diagn. Res., 5: 529-531.

Sultana, S., Begum, N.,Ali, L., Hossain, M.M., Bhowmik, N.B. and Parveen, Z., 2009. Electrophysiological changes of motor nerves in patients with type 2 diabetes mellitus. J. Armed Forces med. Coll., 5: 14-17. https://doi.org/10.3329/jafmc.v5i2.4576

Sultana, S., Begum, N., Ali, L., Hossain, M.M., Bhowmik, N.B., Parveen, S. and Perveen, Z., 2010. Electrophysiological changes of sensory nerves in patients with type-2 diabetes mellitus of different duration. Bangabandhu Sheikh Mujib med. Uni. J., 3: 9-12. https://doi.org/10.3329/bsmmuj.v3i1.5507

Valensi, P., Giroux, C., Seeboth-Ghalayini, B. and Attali, J.R., 1997. Diabetic peripheral neuropathy: Effects of age, duration of diabetes, glycemic control and vascular factors. J. Diab. Compl., 11: 27-34. https:// doi.org/10.1016/S1056-8727(95)00086-0

Vinik, A.I., Holland, M.T., Le Beau, J.M., Liuzzi, F.J., Stansberry, K.B. and Colen, L.B., 1992. Diabetic neuropathies. Diab. Care, 15: 1926-1975. https:// doi.org/10.2337/diacare.15.12.1926

Wiggin, T.D., Sullivan, K.A., Pop-Busui, R., Amato, A., Sima, A.A. and Feldman, E.L., 2009. Elevated triglycerides correlate with progression of diabetic neuropathy. Diabetes, 58: 1634-1640. https://doi. org/10.2337/db08-1771

Wild, S., Roglic, G., Green, A., Sicree, R. and King, H., 2004. Global prevalence of diabetes estimates for the year 2000 and projections for 2030. Diab. Care, 27:1047-1053. https://doi.org/10.2337/ diacare.27.5.1047 